FORSCHUNGSBERICHTE DES LANDES NORDRHEIN-WESTFALEN

Nr. 1121

\title{
Herausgegeben
}

im Auftrage des Ministerpräsidenten Dr. Franz Meyers

von Staatssekretär Professor Dr. h. c. Dr. E. h. Leo Brandt 
Forschungsinstitut für Internationale Technische Zusammenarbeit an der Rheinisch-Westfälischen Technischen Hochscbule Aachen

Dr.pbil. Markus Timmler

\section{Die wirtschaftliche und politische Bedeutung der panafrikanischen Konferenzen}

(Accra, Tunis, Addis Abeba, Tanger)

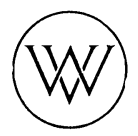

Springer Fachmedien Wiesbaden GmbH 
ISBN 978-3-663-06147-2 ISBN 978-3-663-07060-3 (eBook)

DOI 10.1007/978-3-663-07060-3

Verlags-Nr. 011121

(C) 1962 by Springer Fachmedien Wiesbaden

Ursprünglich erschienen bei Westdeutscher Verlag, Köln und Opladen 1962. 


\section{Inhalt}

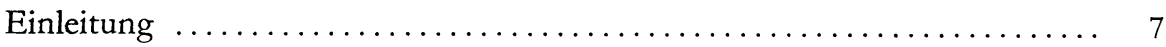

I. Die natürlichen Gegebenheiten $\quad \ldots \ldots \ldots \ldots \ldots \ldots \ldots \ldots \ldots \ldots \ldots$

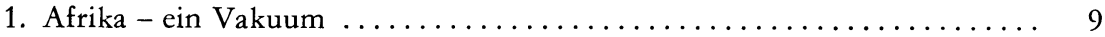

2. Afrika - eine Schatzkammer ......................... 9

3. Verkehrslage und strategische Bedeutung $\ldots \ldots \ldots \ldots \ldots \ldots \ldots \ldots \ldots$

II. Die politischen Voraussetzungen $\ldots \ldots \ldots \ldots \ldots \ldots \ldots \ldots \ldots \ldots \ldots$

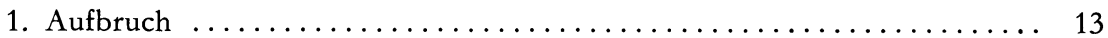

2. Durch Europa ausgelöst ........................... 15

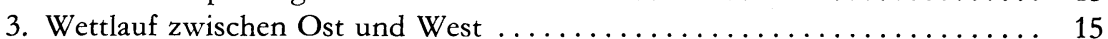

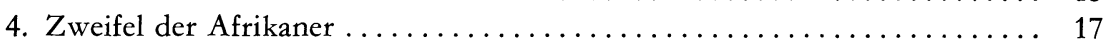

5. Drei Ergebnisse .................................. 18

III. Ablauf und Inhalt der Konferenzen $\ldots . \ldots \ldots \ldots \ldots . . \ldots \ldots$

1. Die Tagungen der »Economic Commission for Africa «............ 19 Erste Tagung vom 29. Dezember 1958 bis 6. Januar 1959 in Addis Abeba ......... 21 Zweite Tagung vom 26. Januar bis 6. Februar 1960 in Tanger................. 22 Dritte Tagung vom 6. bis 18. Februar 1961 in Addis Abeba ................. 22

2. Die Tagungen der »Conference of Independent African States « . . . . . 23 Erste Tagung vom 15. bis 22. April 1958 in Accra ...................... 24

Zweite Tagung vom 14. bis 26. Juni 1960 in Addis Abeba ..................... 24

3. Die Tagungen der $»$ All African People's Conference» ............. 25 Erste Tagung vom 5. bis 13. Dezember 1958 in Accra ................... 26

Zweite Tagung vom 25. bis 30. Januar 1960 in Tunis ....................... 26

Dritte Tagung vom 25. bis 31. März 1961 in Kairo ..................... 26 
IV. Die Bedeutung der »Konferenzen«

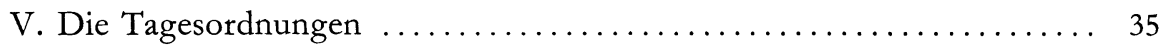

a) Befreiung der Gebiete unter nicht-afrikanischer Herrschaft ......... 35



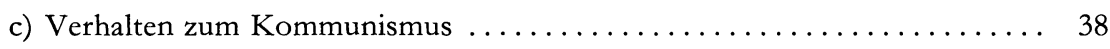

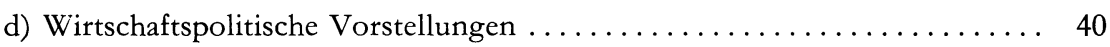

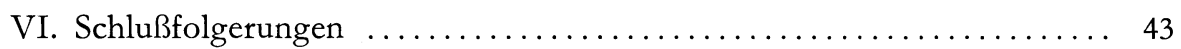

Anlagen (Text jeweils englisch und deutsch):

First Conference of Independent African States (Anlage I) ........... 45

Second Conference of Independent African States (Anlagen II-IV) ....... 48

Literaturverzeichnis . . . . . . . . . . . . . . . . . . . 55 